\title{
Penile Undifferentiated Pleomorphic
}

\section{Sarcoma}

National Cancer Institute

\section{Source}

National Cancer Institute. Penile Undifferentiated Pleomorphic Sarcoma. NCI Thesaurus.

Code C162589.

A rare undifferentiated pleomorphic sarcoma that occurs in the penis. 